\title{
IMPLEMENTATION OF COOPERATIVE LEARNING MODEL TYPE NUMBERED HEAD TOGETHER (NHT) TO TRAIN SCIENCE PROCESS SKILL IN ACID BASE MATTER OF GRADE STUDENTS AT SMAN JOGOROTO JOMBANG
}

\author{
Mulia Sri Rahmawati ${ }^{1}$, Harun Nasrudin*², \\ ${ }^{1}$ Jurusan Kimia, FMIPA, UniversitasNegeri Surabaya \\ *harunnasrudin@unesa.ac.id
}

\begin{abstract}
The purpose of thisresearch isto describe theimplementation ofthe syntax of the numbered heads together (NHT) type of cooperative learning model and the students science process skills when applying the Numbered Heads Together (NHT) type of cooperative learning model to the acid-base material. This research use the One-Group Pretest-Posttest Design. The results of the research are shown as follows: (1) Thee implementation of the syntax of the NHT types off cooperative learningmodel obtained a percentage at three meetings in the first phase of 62.5\%, 75.0\%, $87.0 \%$; the second phase of $75.0 \%, 87.0 \%$, and $100 \%$; the third phase of $75.0 \%, 75.0 \%$, and $100 \%$; the fourth phase of $62.5 \%, 87.0 \%$, and $100 \%$; the fifth phase of $75.0 \%, 87 \%, 100 \%$; the sixth phase $50 \%, 100 \%$, and $100 \%$. (2) Science process skills of students to formulate problems get n-gain values of 0.31 in the medium category, compile hypotheses to get n-gains value off 0.49 in the medium category, collecting data get n-gain values of 1,00 with a high category, analyzing the data get a $n$-gain value of 0.99 witha high category, and make conclusions to get a n-gain value of 0.92 with a high category.
\end{abstract}

Keywords: numbered head together (NHT), science process skills, acid base.

\section{PENDAHULUAN}

Pendidikan didapatkan melalui lembaga formal seperti sekolah. Pada tempat ini, pembelajaran digunakan sebagai pemberi ilmu pengetahuan dan pembelajaran merupakan proses berkembangnya potensi dan membangun suatu karakter peserta didik yang menempuh pendidikan.

$\begin{array}{cccc}\text { Mata pelajaran } & \text { kimia } & \text { adalah } \\ \text { pembelajaran } & \text { yang } & \text { tercantum } & \text { dalam }\end{array}$ pendidikan menengah atas khususnya IPA. Dalam kimia terdiri atas kognitif, ketrampilan, dan afektif yang termuat dalam kompetensi dasar. Kompetensi dasar merupakan turunan dari kompetensi inti yang berisikan afektif, spiritual, dan kognitif. [1]

Kurikulum 2013 memberikan strategi untuk meningkatkan efektivitas pemahaman konsep dengan mengedepankan pengalaman personal peserta didik melalui pendekatan ilmiah (scientific approach). Dalam kegiatan belajar IPA, scientific approach dapat diakukan melalui ketrampilan proses sains. [2].

Materi asam basa menuntut peserta didik untuk pembuktian hipotesis dengan melakukan praktikum, pengumpulan data, analisis data, mengkriteriakan data serta mempresentasikan hasil praktikum. Berdasarkan hasil pra penelitian yang dilakukan di SMAN Jogoroto Jombang terhadap 33 peserta didik kelas XII IPA 2, didapatkan pernyataan yang mengatakan bahwa pembelajaran kimia termasuk pembelajaran yang sulit dengan persentase jawaban peserta didik sebesar $74 \%$. Selain itu sebanyak $97 \%$ peserta didik kelas XII IPA 2 masih kesulitan dalam mengerjakan soal keterampilan proses sains. Serta masih banyak peserta didik kelas XII IPA 2 yang masih kurang aktif dalam bertanya, dimana $71 \%$ peserta didik masih jarang bertanya tentang pembelajaran yang belum dipahami. Dari data tersebut didapatkan kesimpulan bahwa peserta didik masih belum terbiasa 
dengan pembelajaran yang berbasis keterampilan proses sains, maka dari itu perlu dilatihkan KPS dalam proses pembelajaran, seperti merumuskan masalah, menyusun hipotesis, mengumpulkan data, menganalisis data, dan membuat kesimpulan.

Saat ini banyak model pembelajaran yang dapat melatihkan KPS, salah satunya yaitu pembelajaran kooperatif NHTyang memberi arahan ke peserta didik untuk mengerti konsep, arti, dan hubungan akhinya sampai pada suatu kesimpulan. Peserta didik tidak hanya menghafal materi, melainkan berkesempatan untuk berlatih meningkatkan pengertian akan materi yang dipahami. [3]

\section{METODE}

Subyek penelitian ini adalah 33 peserta didik kelas XI IPA 2 di SMAN Jogoroto Jombang dan berdasarkan One Group Pre-test Post-test Design [4].

\section{$\mathrm{O}_{1} \mathrm{X} \mathrm{O}_{2}$}

Pelaksanaan penelitian memiliki 3 tahap yaitu tahap perencanaan, pelaksanaann kegiatan pembelajaran dan analisis data. Tahap perencanaan meliputi persiapan dalam penyusunan perangkat pembelajaran, tahap pelaksanaan yakni kegiatan belajar mengajar menggunakan model kooperatif NHT, dan analisa data yang digunakan yaitu analisa data keterlaksanaan pembelajaran kooperatif tipe NHT dan analisa penilaian keterampilan proses sains.

Penelitian keterlaksanaan model pembelajaran kooperatif tipe NHT ini menggunakan skala persentase untuk mengetahui kualitas keterlaksanaan fase pembelajaran digunakan rumus sebagai berikut:

$$
\begin{aligned}
& \% \text { keterlaksanaan } \\
& =\frac{\sum \text { skor fase yang terlaksana }}{\sum \text { skor maksimal fase secara keseluruhan }} \times 100 \%
\end{aligned}
$$

Perhitungan persentase dilakukan di tiap fase pembelajaran dan keseluruhan aspek penilaian. Keterlaksanaan dikatakan berhasil apabila persentase yang diperoleh $\geq 61 \%$. [5]

Hasil KPS didapatkan dari hasil pre-test dan post-test pada materi asam basa. Perhitungan skor menggunakan rumus berikut.

Skor ketrampilan proses sains = $\frac{\text { skor yang diperoleh }}{\text { skor maksimal }} \times 100$

Analisis keterampilan proses sains dilakukan dengan menganalisis hasil pre-test dan post-test peserta didik pada materi asam basa menggunakan nilai $n$-gain. Persamaan untuk menetukan nilai indeks gain sebagai berikut :

$$
n-\text { gain }=\frac{\text { hasil posttest }- \text { hasil } \text { pretest }}{\text { nilai } \text { maksimal }- \text { hasil pretest }}
$$

Dari $n$-gain yang didapatkan kemudian dimasukkan ke dalam kategori sebagai berikut :[6]

Tabel 2 Kriteria $n$-gain

\begin{tabular}{cl}
\hline n-gain & Kriteria \\
\hline $0,70 \leq \mathrm{g} \leq$ & \multirow{2}{*}{ Tinggi } \\
1,00 & \\
\hline $0,30 \leq \mathrm{g} \leq$ & \multirow{2}{*}{ Menengah } \\
0,70 & \\
\hline $0,00 \leq \mathrm{g} \leq$ & \multirow{2}{*}{ Rendah } \\
0,30 & \\
\hline
\end{tabular}

\section{HASIL DAN PEMBAHASAN}

Hasil penelitian dan pembahasan diuraikan sebagai berikut.

\section{Keterlaksanaan Kooperatif Tipe (NHT)}

Keterlaksanaan ini bertujuan mengetahui terlakukannya sintaks dalam melatihkan ketrampilan proses sains. Keterlaksanaan model pembelajaran dikatakan baik apabila masuk dalam rentang persentase kualitas keterlaksanaan mencapai 61\% - 80\% [5].

Pembelajaran kooperatif tipe NHT meningkatkan semangat kerja sama peserta didik. [7]. Keterlaksanaan model pembelajaran kooperatif dalam 3 kali pertemuan disajikan dalam Gambar1. 


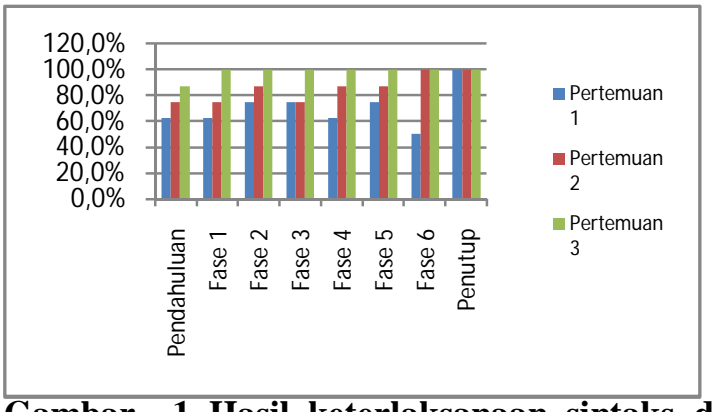

Gambar 1 Hasil keterlaksanaan sintaks di tiap pertemuan

Berdasarkan Gambar 1 keterlaksanaan model pembelajaran kooperatif tipe NHT di tiga kali pertemuan di fase awal memberikan tujuan mendapatkan rata-rata persentase kualitas keterlaksanaan sebesar 62,5\%; 75,0\% dan $87,0 \%$. Pada fase kedua menyajikan informasi mendapatkan rata-rata persentase kualitas keterlaksanaan sebesar $75 \% ; 87,0 \%$ dan $100 \%$. Pada fase ketiga mengelompokkan peserta didik memperoleh hasil kualitas keterlaksanaan sebesar 75\%; 75,0\%; $100 \%$. Pada fase keempat membimbing kelompokkelompok bekerja dan belajar mendapatkan rata-rata persentase kualitas keterlaksanaan sebesar $62,5 \%$; 87,0\% dan $100 \%$. Fase kelima, evaluasi mendapatkan rata-rata persentase kualitas keterlaksanaan sebesar 75,0\%; 87,0\% dan $100 \%$. Fase keenam penutup yakni memberikan penguatan atau penghargaan mendapatkan rata-rata persentase kualitas keterlaksanaan sebesar 50\%; 100\% dan 100\%. Fase keenam di pertemuan pertama memperoleh persentase $\leq 61 \%$ dikarenakan ada salah satu aspek yang tidak terlaksana saat melakukan pembelajaran.

Pada tahap berpikir bersama (HeadTogether), tahap dimana pengembangan kognitif dan ketrampilan secara penuh dalam suasana belajar yang aktif dan sportif.[8].

Berdasarkan uraian penjelasan diatas, keterlaksanaan model pembelajaran kooperatif tipe NHT selama tiga kali pertemuan diperoleh persentase yang meningkat di tiap pertemuan.

\section{Ketrampilan Proses Sains}

Dalam penelitian ini, peneliti mengambil lima komponen keterampilan proses sains yaitu mengajukan rumusan masalah, menyusun dugaan sementara, mengumpulkan data, menganalisa data dan menarik simpulann. Keterampilan proses sains dikatakan terlatih jika mendapatkan hasil $(\mathrm{g}) \geq$ 0,7 . Sesuai dengan penelitian oleh Lati, dkk didapatkan hasil yang meningkat dalam keterampilan proses sains terintegrasi [9]. Berikut tabel hasil pretest dan hasil posttest tiap komponen ketrampilan proses sains:

Tabel 3 Hasil pre-test dan post-test tiap komponen KPS

\begin{tabular}{ccccc}
\hline $\begin{array}{c}\text { Komponen } \\
\text { KPS }\end{array}$ & $\begin{array}{c}\text { Pre } \\
\text { test }\end{array}$ & $\begin{array}{c}\text { Post } \\
\text { test }\end{array}$ & $\begin{array}{c}\boldsymbol{n} \text { - } \\
\text { gain }\end{array}$ & Kategori \\
\hline $\begin{array}{c}\text { Merumuskan } \\
\text { masalah }\end{array}$ & 61,1 & 73,3 & 0,3 & Sedang \\
\hline $\begin{array}{c}\text { Menyusun } \\
\text { Hipotesis }\end{array}$ & 62,2 & 80,8 & 0,4 & Sedang \\
\hline $\begin{array}{c}\text { Mengumpulka } \\
\text { n Data }\end{array}$ & 28,2 & 100 & 1,0 & Tinggi \\
\hline $\begin{array}{c}\text { Menganalisis } \\
\text { Data }\end{array}$ & 18,1 & 98,9 & 0,9 & Tinggi \\
\hline $\begin{array}{c}\text { Membuat } \\
\text { Kesimpulan }\end{array}$ & 13,13 & 92,92 & 0,92 & Tinggi \\
\hline
\end{tabular}

Berdasarkan Tabel3 komponen KPS merumuskan masalah dan menyusun hipotesis mendapatkan kategori sedang karena dalam merumuskan masalah, peserta didik mendapatkan nilai yang paling rendah di bagian membuat pertanyaan masalah. Sedangkan di komponen membuat hipotesi speserta didik masih merasa kesulitan untuk membuat dugaan sementara yang muncul dalam fenomena. Ketiga komponen KPS yaitu mengumpulkan data, menganalisa data, dan menarik simpulan, peserta didik mampu dalam menjawab pertanyaan yang berkaitan dengan ketiga komponen tersebut dan mendapatkan kategori $n$-gain yang tinggi

KPS dapat terlatih dengan baik menggunakan model pembelajaran kooperatif tipe NHT didukung teori perkembangan Vygotsky. Berkomunikasi dengan teman lain memicu tumbuhnya pemikiran baru dan memperbanyak perkembangan intelektual peserta didik. Seseorang berusaha 
menghubungkan ilmu baru dengan ilmu awal lalu mengkonstruksi ilmu baru dalam usaha memperoleh suatu pemahaman [10].

\section{SIMPULAN DAN SARAN}

Sesuai hasil analisa data penelitian, diambil kesimpulan dalam keterlaksanan model pembelajaran kooperatif tipe NHT melatihkan ketrampilan proses sains dapat terlaksana dengan sangat baik. Hal tersebut ditunjukan dengan keterlaksanaan sintaks model pembelajaran kooperatif tipe NHT memperoleh persentase di tiga kali pertemuan di fase pertama sebesar $62,5 \%, 75,0 \%, 87,0 \%$; fase kedua sebesar $75,0 \%, 87,0 \%$, dan $100 \%$; fase ketiga sebesar $75,0 \%, 75,0 \%$, dan $100 \%$; fase keempat sebesar $62,5 \%, 87,0 \%$, dan $100 \%$; fase kelima sebesar $75,0 \%, 87 \%$, $100 \%$; fase keenam sebesar $50 \%, 100 \%$, dan $100 \%$ mendapat kriteria baik sekali karena setiap fase memperoleh persentase $\geq 61 \%$ terkecuali di fase keenam mendapatkan kriteria cukup di pertemuan pertama. Hasil belajar ranah ketrampilan proses sains tiap komponen ketrampilan proses sains untuk membuat rumusan masalah mendapatkan nilai $n$-gain sebesar 0,31 (sedang), menyusun hipotesis sebesar $0,49 \quad$ (sedang), mengumpulkan data sebesar 1,00 (tinggi), menganalisis data sebesar 0,99 (tinggi), dan membuat kesimpulan sebesar 0,92 (tinggi). Dari nilai tersebut menandakan ketrampilan prose ssains dapat terlatihkan menggunakan model pembelajaran kooperatif tipe NHT karena seluruh komponen mendapatkan nilai $n$-gain $\geq 0,7$.

Saran yang diberikan sebaiknya dalam pembelajaran dilakukan penekanan kembali pada komponen merumuskan masalah dan menyusun hipotesis dalam melatihkan KPS karena hasil n-gain yang diperoleh masih rendah dibandingkan dengan komponen keterampilan proses sains yang lain. Lebih ditekankan juga dalam materi Bronsted-Lowry tentang pasangan asam basa konjugasi dan lebih sering mengajak peserta didik untuk berani menyampaikan pendapatnya agar peserta didik dapat mengungkapkan pendapatnya dengan baik dan tidak takut salah.

\section{DAFTAR PUSTAKA}

[1] Brotosiswojo. 2011. Hakekat Pembelajaran MIPA dan Kiat Pembelajaran Kimia di Perguruan Tinggi. Jakarta: Depdiknas

[2] Putri, One Oktavianing \& Nasrudin, Harun. 2018. Penerapan Model Pembelajaran Kooperatif Tipe Numbered HeadsTogether(NHT) Untuk Melatihkan Keterampilan Proses Sains Peserta Didik Pada Materi Kesetimbangan Kimia Kelas XI MAN Kota Mojokerto. UNESA Journal of Chemical Education Vol. 7, No.3, pp. 340-343

[3] Kemendikbud. 2016. Salinan Lampiran Permendikbud Nomor 24 Tahun2016 tentang Kompetensi Inti dan Kompetensi Dasar. Jakarta: Kemendikbud

[4] Sugiyono. 2010. Metode Penelitian Pendidikan (Pendekatan Kuantitatif, Kualitatif, dan $R \& D)$. Bandung: Alfabeta

[5] Riduwan.2015.Variabel-variabel Penelitian. Bandung: Alfabetaa

[6] Hake, Richardz. R. 1998. Analyzing Change or Gain Scores.http://www.physics.indiana.edu/ di/AnalyzingChange-Gain.pdf Diakses dari laman web tanggal 18 November 2018

[7] Hudah, Miftahul. 2011. Cooperative Learning. Yogyakarta : Pustaka Belajar.

[8] Rohmah, Datin Mufidhatur \& Nasrudin, Harun.2015. Implementasi Model Pembelajaran Kooperatif Tipe Numbered Head Together (NHT) Untuk Melatihkan Keterampilan Berpikir Kritis Siswa Pada Materi Stokiometri Di SMAN 3 Lamongan.. UNESA Journal of Chemical Education Vol. 4, No.2, pp. 218-223

[9] Lati, Wichai, Supasornn, Saksri\&Promarak, Vinch. 2012. Enhancementt Of Learning Achievement and Integrated Science Process Skills Using Science Inquiry Learning Activies of Chemical Reaction Rates. Sciversi SCIENCE DIRECT Procedia - Social Behavioral Sciences 46. 4471-4475. https://www.sciencedirect.com/science/art icle/pii/S1877042812020150._diakses pada tanggal 25 Juni 2019

[10] Ibrahim. 2000. Pembelajaran Kooperatif. Surabaya: Unesa Press 